Bundesgesundheitsbl 2019 $62: 380$

https://doi.org/10.1007/s00103-019-02923-z

Online publiziert: 4. März 2019

(c) Der/die Autor(en) 2019

\section{Sabine Bartholomeyczik}

Department für Pflegewissenschaft, Fakultät für Gesundheit, Universität Witten/Herdecke, Witten, Deutschland

\section{Erratum zu:}

Bundesgesundheitsbl 2019

https://doi.org/10.1007/s00103-019-

02878-1

Der Artikel Prävention von Mangelernährung in der stationären Pflege am Beispiel des DNQP-Expertenstandards „Ernährungsmanagement" wurde ursprünglich am 22. Januar 2019 ohne „Open Access“ online auf der Internetplattform des Verlags publiziert. Die Bundeszentrale für gesundheitliche Aufklärung hat sich als Sponsor jedoch nachträglich für eine „Open Access“Veröffentlichung entschieden. Das Urheberrecht des Artikels wurde deshalb im Februar 2019 in (C) Der/die Autor(en) 2019 geändert. Der Artikel wird nun unter der Namensnennung 4.0 International (https://creativecommons.org/ licenses/by/4.0/deed.de) veröffentlicht, welche die Nutzung, Vervielfältigung, Bearbeitung, Verbreitung und Wiedergabe in jeglichem Medium und Format erlaubt, sofern Sie den/die ursprünglichen Autor(en) und die Quelle ordnungsgemäß nennen, einen Link zur Creative Commons Lizenz beifügen und angeben, ob Änderungen vorgenommen wurden.

\section{Korrespondenzadresse \\ Prof. Dr. Sabine Bartholomeyczik \\ Department für Pflegewissenschaft, Fakultät für Gesundheit, Universität Witten/Herdecke Stockumer Str. 12, 58453 Witten, Deutschland sabine.bartholomeyczik@uni-wh.de}

Open Access. Dieser Artikel wird unter der Creative Commons Namensnennung 4.0 International Lizenz (http://creativecommons.org/licenses/by/4.0/deed. de) veröffentlicht, welche die Nutzung, Vervielfältigung, Bearbeitung, Verbreitung und Wiedergabe in jeglichem Medium und Format erlaubt, sofern Sie den/die ursprünglichen Autor(en) und die Quelle ordnungsgemäßnennen, einen Linkzur Creative Commons Lizenz beifügen und angeben, ob Änderungen vorgenommen wurden. 